\title{
Thermal Decomposition of New and Aged LX-04 and PBX 9501
}

\author{
T. D. Tran, C. Tarver, D. J. Idar, W. A. Rodin
}

This article was submitted to $24^{\text {th }}$ Aging, Compatibility and Stockpile Stewardship Conference, Amarillo, TX., April 30- May 2, 2002

\section{April 9, 2002}

U.S. Department of Energy

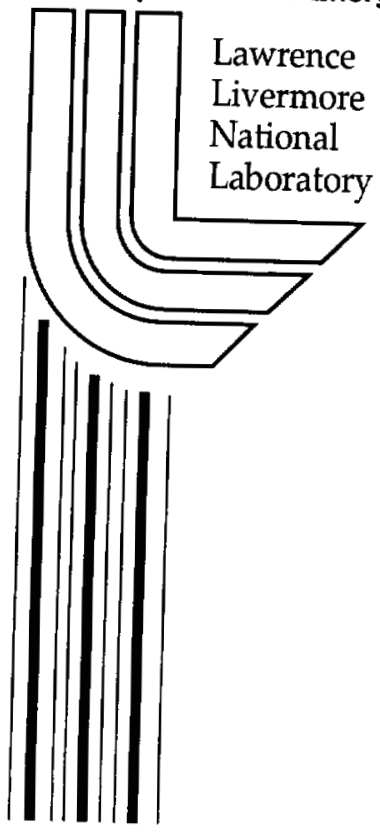




\section{DISCLAIMER}

This document was prepared as an account of work sponsored by an agency of the United States Government. Neither the United States Government nor the University of California nor any of their employees, makes any warranty, express or implied, or assumes any legal liability or responsibility for the accuracy, completeness, or usefulness of any information, apparatus, product, or process disclosed, or represents that its use would not infringe privately owned rights. Reference herein to any specific commercial product, process, or service by trade name, trademark, manufacturer, or otherwise, does not necessarily constitute or imply its endorsement, recommendation, or favoring by the United States Government or the University of California. The views and opinions of authors expressed herein do not necessarily state or reflect those of the United States Government or the University of California, and shall not be used for advertising or product endorsement purposes.

This is a preprint of a paper intended for publication in a journal or proceedings. Since changes may be made before publication, this preprint is made available with the understanding that it will not be cited or reproduced without the permission of the author.

This work was performed under the auspices of the United States Department of Energy by the University of California, Lawrence Livermore National Laboratory under contract No. W-7405-Eng-48.

This report has been reproduced directly from the best available copy.

Available electronically at http://www.doc.gov/bridge

Available for a processing fee to U.S. Department of Energy

And its contractors in paper from

U.S. Department of Energy

Office of Scientific and Technical Information

P.O. Box 62

Oak Ridge, TN 37831-0062

Telephone: (865) 576-8401

Facsimile: (865) 576-5728

E-mail: reports@adonis.osti.gov

Available for the sale to the public from

U.S. Department of Commerce

National Technical Information Service

5285 Port Royal Road

Springfield, VA 22161

Telephone: (800) 553-6847

Facsimile: (703) 605-6900

E-mail: orders@ntis.fedworld.gov

Online ordering: http://www.ntis.gov/ordering.htm

$\mathrm{OR}$

Lawrence Livermore National Laboratory

Technical Information Department's Digital Library

http://www.llnl.gov/tid/Library.html 


\title{
THERMAL DECOMPOSITION OF NEW AND AGED LX-04 AND PBX 9501
}

\author{
T. D. Tran and C. Tarver \\ Lawrence Livermore National Laboratory, P. O. Box 808, Livermore, CA 94551 \\ D. J. Idar \\ Los Alamos National Laboratory, P. O. Box 1663, Los Alamos, NM 87545
}

and

W. A. Rodin

BWXT Pantex, P. O. Box 30020, Amarillo, TX 79120

\begin{abstract}
One-Dimensional-Time-To-Explosion (ODTX) experiments were conducted to study the thermal decomposition of new and aged LX-04, PBX 9501, HMX class 1 and class 2, Estane and Estane/BDNPA-F (PBX 9501 plasticized-binder) materials. New and aged LX-04 showed comparable decomposition kinetics. The data for aged PBX 9501 showed slightly longer explosion times at equivalent temperatures. Analysis of the error in time measurement is complicated by several experimental factors but the small time change appears to be experimentally significant. The results suggest that aged PBX 9501 is slightly more thermally stable.

The thermal decomposition of these materials were modeled using a coupled thermal and heat transport code (chemical TOPAZ) using separate kinetics for HMX and binder decomposition. The current kinetic models describe the longer explosion times by the loss of plasticizer-binder constituent, which was more thermally reactive.
\end{abstract}

\section{INTRODUCTION}

An integrated One-Dimensional-Time-To-Explosion (ODTX) experimental and chemical kinetic decomposition modeling effort was undertaken to determine whether aged HMX-based plastic bonded explosives, such as LX-04 and PBX 9501, are more thermally sensitive than new materials. The ODTX data on aged specimens were obtained and compared directly to historical data that were available on these materials at LLNL $(1,2)$ and at Pantex. Recent experiments also included tests on pure HMX (both classes 1 and 2), binder components used in both these composites and newer batches of PBX 9501. The results are used for developing new kinetic models for pure HMX and the composite binder and their plastic bonded composites. The upgraded HMX model incorporates kinetics for the $\beta-\delta$ HMX phase transition (3), which precedes the exothermic decomposition.

ODTX experiments have been used extensively to study the thermal explosions of a wide variety of high explosives (HE) including many $\mathrm{HMX}$-based formulations $(1-2,4-5)$. The test involves heating a $12.7 \mathrm{~mm}$-diameter $\mathrm{HE}$ sphere confined in two pre-heated constant-temperature aluminum anvils until the material explodes. The confinement is set at $150 \mathrm{MPa}$. The time to explosion is the elapsed time between the sample insertion (and anvil closure) and the rupture of containment. The time to explosion as a function of the temperature provides useful kinetic information on the material decomposition.

\section{EXPERIMENTAL}

All experiments at LLNL were conducted on an ODTX apparatus that was developed by Catalano and co-workers (1). Tests at Pantex were done on an identical unit under similar conditions. The ODTX experimental procedure and the apparatus are described below. Additional details are presented elsewhere $(1-2,6)$.

The main components of the test are two cylindrical aluminum anvils (75-mm diameter $\mathrm{x} 50$ mm long, $6061 \mathrm{~T} 6 \mathrm{Al}$ ). Each anvil contains a $12.7 \mathrm{~mm}$-diameter hemispherical cavity and a 18.5 mm-diameter circular groove with a knife-edge bottom to accommodate a copper O-ring seal (Vacuum Products Corp., GK-075). A circular copper ring clamped between the two knife-edges 
Table 1. History and characteristics of ODTX samples. Data are from LLNL unless indicated.

\begin{tabular}{|c|c|c|c|}
\hline & ODTX date & $\begin{array}{l}\text { Sample } \\
\text { preparation }\end{array}$ & $\begin{array}{l}\text { Ave. } \\
\text { density*, } \\
\mathrm{g} / \mathrm{cm}^{3}\end{array}$ \\
\hline $\begin{array}{l}\text { New (historical) LX-04 } \\
85 \text { wt } \% \text { HMX, } 15 \text { wt\% Viton A }\end{array}$ & 1986 & $\begin{array}{l}\text { Die-pressed hemi } \\
\text { Glued with epoxy }\end{array}$ & 1.865 \\
\hline Aged LX-04 & 2000 & $\begin{array}{l}\text { Machined into sphere } \\
\text { from cored samples }\end{array}$ & 1.874 \\
\hline $\begin{array}{l}\text { New (historical) PBX 9501 (MH } \\
622-7) 95 \text { wt } \% \text { HMX, 2.5 wt\% } \\
\text { Estane, } 2.5 \text { wt\% BDNPA-F }\end{array}$ & 1981 & $\begin{array}{l}\text { Die-pressed hemi } \\
\text { Glued with epoxy }\end{array}$ & 1.785 \\
\hline $\begin{array}{l}\text { Aged PBX } 9501,(\text { HOL77H685- } \\
001: 94.9 \text { wt } \% \text { HMX, } 2.5 \text { wt } \% \\
\text { Estane, } 2.4 \text { wt } \% \text { BDNPA-F } * *)\end{array}$ & 2000 & $\begin{array}{l}\text { Machine into sphere from } \\
\text { cored samples }\end{array}$ & 1.845 \\
\hline $\begin{array}{l}\text { HMX grade B, Class } 1 \\
(\text { Hol94M033-024) }\end{array}$ & 2000 & Die-pressed into sphere & 1.772 \\
\hline $\begin{array}{l}\text { HMX grade B, Class } 2 \\
(\text { Hol98E } 243-020)\end{array}$ & 2000 & Die-pressed into sphere & 1.730 \\
\hline Estane & 2000 & Die-pressed into sphere & \\
\hline \begin{tabular}{lllll|}
$50 \quad$ wt $\%$ & Estane & $/$ & 50 & wt $\%$ \\
BDNPA/F & & & & \\
\end{tabular} & 2000 & Hand-rolled into sphere & \\
\hline $\begin{array}{l}\text { New (historical) PBX } 9501 \\
\text { (Lot } 730-010 \text { ) }\end{array}$ & 1990 (Pantex) & $\begin{array}{l}\text { Die-pressed hemi } \\
\text { Glued with epoxy }\end{array}$ & 1.822 \\
\hline $\begin{array}{l}\text { New PBX 9501 } \\
\text { (Lot 99064-164-01) }\end{array}$ & 2000 (Pantex) & $\begin{array}{l}\text { Hemi machined from } \\
\text { cored samples } \\
\text { Glued with epoxy }\end{array}$ & 1.833 \\
\hline $\begin{array}{l}\text { New PBX 9501 } \\
\text { (Lot 99071-164-01) }\end{array}$ & 2000 (Pantex) & $\begin{array}{l}\text { Hemi machined from } \\
\text { cored samples } \\
\text { Glued with epoxy }\end{array}$ & 1.835 \\
\hline
\end{tabular}

*Density derived from average weight divided by sample volume $\left(1.07 \mathrm{~cm}^{3}\right)$

** Compositional analysis performed on aged library lot specimens reported in 1999 (7)

provides a gas-tight seal when two anvils are pressed together. The upper anvil is mounted to the piston surface of a hydraulic piston (16-ton double-acting hydraulic cylinder, RD-166, Enerpac). The test confinement pressure is $150 \mathrm{MPa}$. The two anvils are heated by two $1000 \mathrm{~W}$ heating cups. The anvil temperature is controlled by a thermocouple inserted in an aluminum disc placed between the two anvils. The explosion is timed acoustically by a microphone and an analog timer. The system is semi automatic and the test is conducted remotely.

Sample preparation - Due to available technology and nature of the stock materials, the ODTX spheres at both laboratories were prepared in different ways. Historical samples at LLNL were die-pressed into hemispheres and then glued together with Permabond $910(<1 \mathrm{wt} \%)$ prior to testing. Recent aged LX-04 and PBX 9501 were available as $15.8 \mathrm{~mm}$-diameter right cylinders, which were cored from a isostatically pressed hemisphere. They were then machined directly into spheres for testing. Estane samples were pressed to shape in a spherical die without heating. Estane/BDNPA-F (50/50) compound was hand rolled into partially spherical specimens because it did not press well. All spherical samples at Pantex were made by gluing 2 hemispheres together with Permabond 910. Depending on the stock materials, hemispherical parts were either directly pressed or machined from larger billets. Relevant history and processing conditions for various materials are summarized in Table 1. 


\section{EXPERIMENTAL RESULTS AND DISCUSSION}

The explosion times for HMX class 1, HMX class 2, 'new' LX04 (data reported in reference 1) and aged LX-04 as functions of inverse temperatures at $150 \mathrm{MPa}$ confinement are shown in Figure 1. The time-inverse temperature curves consist of several linear regions, indicative of fairly complex decomposition processes. At the lowest temperatures $\left(<205^{\circ} \mathrm{C}\right)$ and longest times, thermal explosions may involve pressure bursts where gaseous reaction products exceeded the confinement pressure and popped the anvils open. Such events produce less noise and less damage to the $\mathrm{Al}$ anvils. In the highest temperature regime, accelerated decomposition in region close to the sample surface may cause thermal runaway in only part of the sphere. Such events also cause less damage to the anvils. In contrast, the reactions in the intermediate temperature region where isothermal conditions exist are most violent, yielding deep and large cavities. We have presented and discussed such general trends for several materials $(5,6)$.

The times to explosion are fairly similar for both new and 229-month-old aged LX-04. In addition to age, several experimental factors are different for these two sets of data such as sample type and time separation between the experiments. The effects of sample type (hemi-glued with Permabond 910 and full spheres) were tested for a variety of $\mathrm{HE}$ samples (such as TNT, ammonium perchlorate-containing propellants) and were found to be negligible. The effects of apparatus upgrades, system accuracy and other systematic errors associated with the long time separation between the tests is difficult to assess. The available data for several sets of materials (e.g., TNT, PBX 9501 below and other materials) over several years show good agreement. Selected reproducibility studies with TNT using the old ODTX system (used in this work) showed a standard error of $5.5 \%$ (1 standard deviation). The explosion times for both new and aged LX-04 specimens are within this experimental error range. Tests with PBX 9501 with the new ODTX unit under more controlled conditions (calibrated resistive thermal devices, uniform sample densities, long pre-soak, etc.) showed significantly more reproducibility $( \pm 2.5 \%)$.

The results for both HMX class 1 and class 2 are also included in Figure 1. This is the first time that pure HMX was measured. The slightly larger explosion times in LX-04 (relative to pure HMX) are attributable to the presence of Viton A binder. The binder phase serves as a heat sink, which retards the decomposition. The HMX data tracked those for LX-04 well, suggesting that HMX decomposition dominates LX-04 thermal stability. This is consistent with our assumption in previous works on the thermal behavior of HMX-based formulations containing non-reactive binder such as Viton A. Tarver and Tran discuss in more detail the effects of binder type and binder contents on the thermal behavior of HMX-based formulations in another paper (6).

Figure 2 shows the times to explosion for new and aged (191 months old) PBX 9501. The results for new materials represent both historical (done on new samples at the time) and recent data on new batches of materials. Works at LLNL and Pantex are included. The data for Estane/BDNPA-F binder specimens are also obtained. Tests with pure Estane did not show any positive events (no reaction as recorded by the acoustic sensor and post-test anvil inspection).

Despite the differences in material and experimental variabilities in 20-year time separation, LLNL tests on two new PBX 9501 batches showed comparable explosion times over the temperature range between $180-280^{\circ} \mathrm{C}$. The reproducibility of these two sets of data demonstrates the higher limit of the experimental accuracy of this system.

The results for several formulations from tests done independently at both laboratories show excellent agreement. The explosion time-inverse temperature clearly represents the characteristic thermal ignition behavior of PBX 9501. There is a slight separation between the data from both laboratories, equivalent to a few degrees differences in the temperature scale. This can be attributed to experimental variability in the set-ups and the accuracy of thermocouples (i.e., \pm $2^{\circ} \mathrm{C}$ ). We have reported a small shift in explosion times due to a small temperature difference in two separate ODTX apparatuses at LLNL (8). Furthermore, other historical ODTX data at LLNL and Pantex also show a small offset similar to one seen here for PBX 9501.

Compared to the historical data at LLNL (Pantex-formulated PBX 9501), the aged PBX 9501 consistently exhibited slightly longer times to explosion for temperatures above $210^{\circ} \mathrm{C}$. The time differences are about 50-100 seconds. They are most easily observed in the region between $245-270^{\circ} \mathrm{C}$ where the explosion times are between 30 and 200 seconds. The longer 


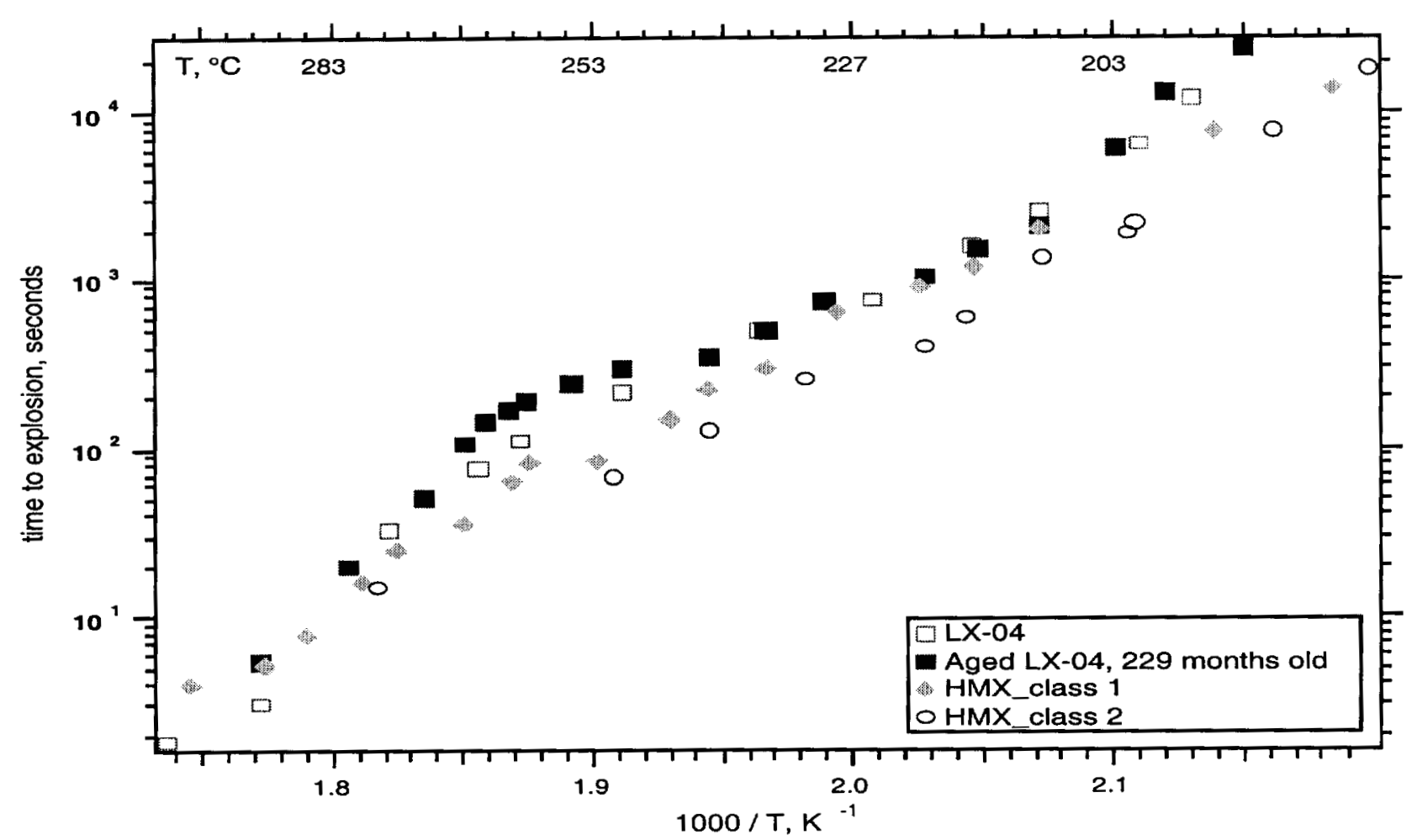

Figure 1. Time to explosion versus inverse temperature for new, aged LX-04 and HMX classes $1 \& 2$. One standard deviation $(1 \sigma)$ error bar is the size of the symbol (e.g., at $250^{\circ} \mathrm{C}$ ) or less.

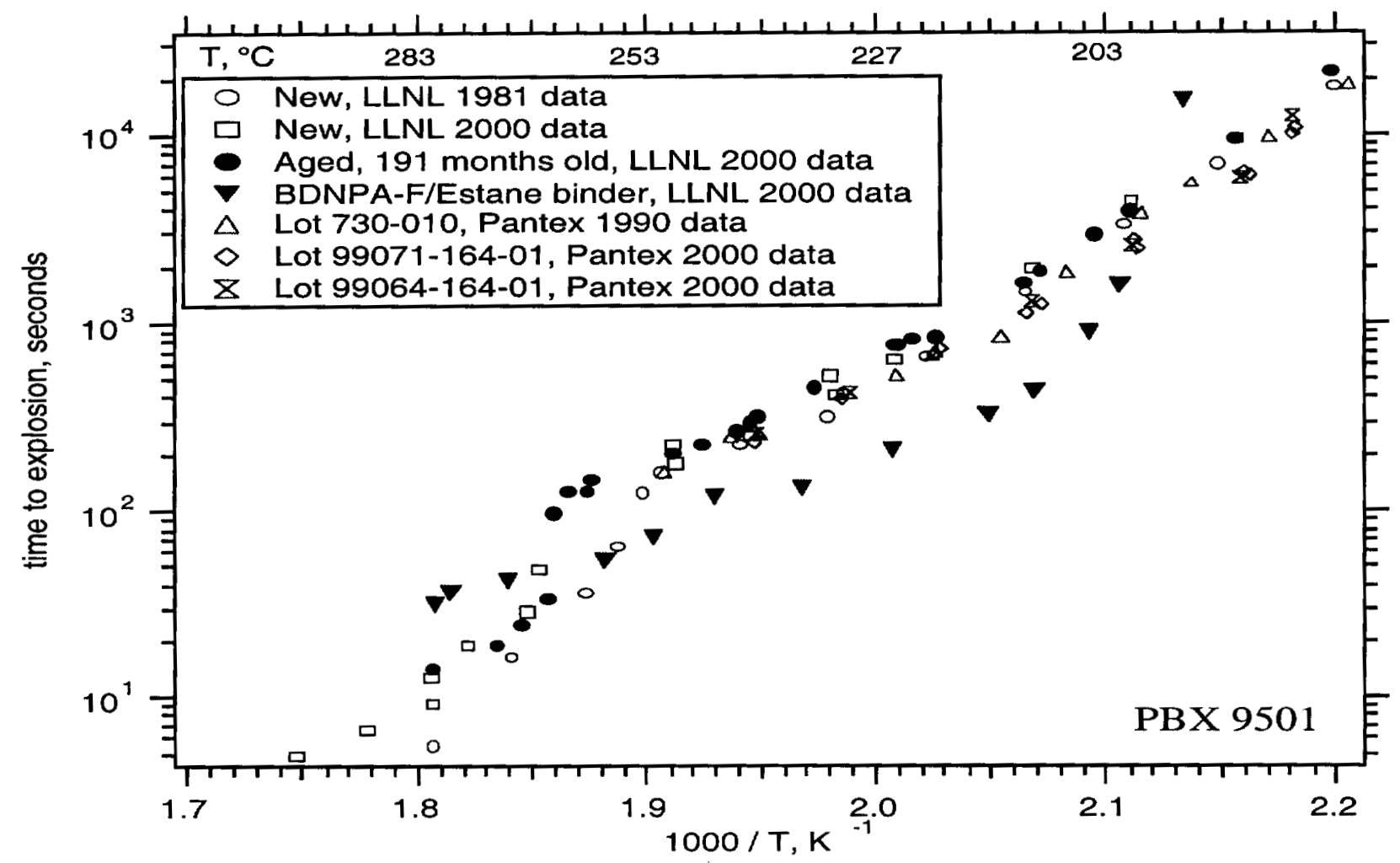

Figure 2. Time to explosion for new and aged PBX 9501, and Estane/BDNPA-F binder specimens. Pure Estane spheres were not reactive with temperatures as high as $300^{\circ} \mathrm{C}$. One standard deviation $(1 \sigma)$ error bar is the size of the symbol (e.g., at $250^{\circ} \mathrm{C}$ ) or less. 
explosion times in aged specimens ( 100 seconds) are significantly larger than expected standard errors $(\sim 10 \mathrm{~s})$. These changes, therefore, reflect the slower decomposition kinetics of the aged materials and not test variabilities.

Understanding of the possible changes in the thermal behavior of aged specimens is complicated by the lack of material compositional and detailed processing history. The surveillance data on aged PBX 9501 show a trend that the Estane molecular weight is decreasing with time and that nitroplasticizer migrates into other components at certain locations. The loss of the nitroplasticizer (NP) content, however, occurs within a small volume and the bulk NP concentration remains within specifications. The effects of Estane decreased molecular weight or lower NP concentration (albeit small) on PBX 9501 decomposition is not yet well understood. Estane/BDNPA-F ODTX data (see Figure 2) clearly showed more reactivity and influence the thermal behavior of PBX 9501. The thermal effects of this component on the composite explosion times need to be investigated further. The densities of aged materials in recent tests are somewhat higher than those for historical data from earlier work (see Table 1). This density effect and other experimental variables, such as material heterogeneities, on the thermal decomposition of PBX 9501 have not been studied. At this point, we cannot attribute the measured longer explosion times in aged specimens to any observable changes in material properties.

Reaction violence - The thermal explosions of LX-04 and PBX 9501 are generally among the most violent reactions we have experienced, producing loud events with large sample cavity increase and no residues. The violence of the thermal explosions in ODTX apparatus can be correlated to the increase in the cavity volume. The cavity volume was measured gravimetrically by weighing the amount of soap/water solution that filled the cavity. ODTX experiments are more violent in the intermediate temperature region where reaction conditions are isothermal, resulting in most of the samples being consumed. The volume increases tend to be scattered but the results did not show any obvious difference in the violence of the thermal responses of new or aged materials. We will report the data in another publication (6).

Kinetic models for HMX-based PBX composites - Thermal decomposition kinetic models have been reported for HMX-containing formulations. We now have pure HMX data to modify these models. The decomposition of $\mathrm{HMX}$ is modeled as a 4 -step process $(3,6)$. The mechanism for the decomposition of HMX (4 steps), BDNPA-F (2 steps) and Estane (one-step) is shown below.

HMX $\beta \rightarrow$ HMX $\delta$ phase transition

HMX thermal decomposition (3 steps)

$\mathrm{HMX} \rightarrow \mathrm{CH}_{2} \mathrm{NNO}_{2}$

$\mathrm{CH}_{2} \mathrm{NNO}_{2} \rightarrow \mathrm{CH}_{2} \mathrm{O}, \mathrm{N}_{2} \mathrm{O}, \mathrm{HCN}, \mathrm{HNO}$

$\mathrm{CH}_{2} \mathrm{O}, \mathrm{N}_{2} \mathrm{O}, \mathrm{HCN}, \mathrm{HNO}_{2} \rightarrow \mathrm{N}_{2}, \mathrm{H}_{2} \mathrm{O}, \mathrm{CO}, \mathrm{CO}_{2}$

BDNPA/F thermal decomposition (2 steps)

$\mathrm{BDNPA} / \mathrm{F} \rightarrow$ intermediates

Intermediates $\rightarrow \mathrm{N}_{2}, \mathrm{H}_{2} \mathrm{O}, \mathrm{CO}, \mathrm{CO}_{2}$

Estane thermal decomposition (one step)

Estane $\rightarrow$ products

This new HMX model includes the beta-to-delta solid phase transition kinetics (3). This phase change is treated separately from the other endothermic processes that precede the exothermic decomposition. Arrhenius kinetics are used for these reactions.

Since the surveillance data for LX-04 showed no change in the composition with aging and the explosion times for new and aged materials are comparable, the same kinetic model is used for both composites. The calculated times to explosion are in good agreement with the experimental values over most of the temperature ranges. Since Viton A is not reactive thermally, it is treated as 


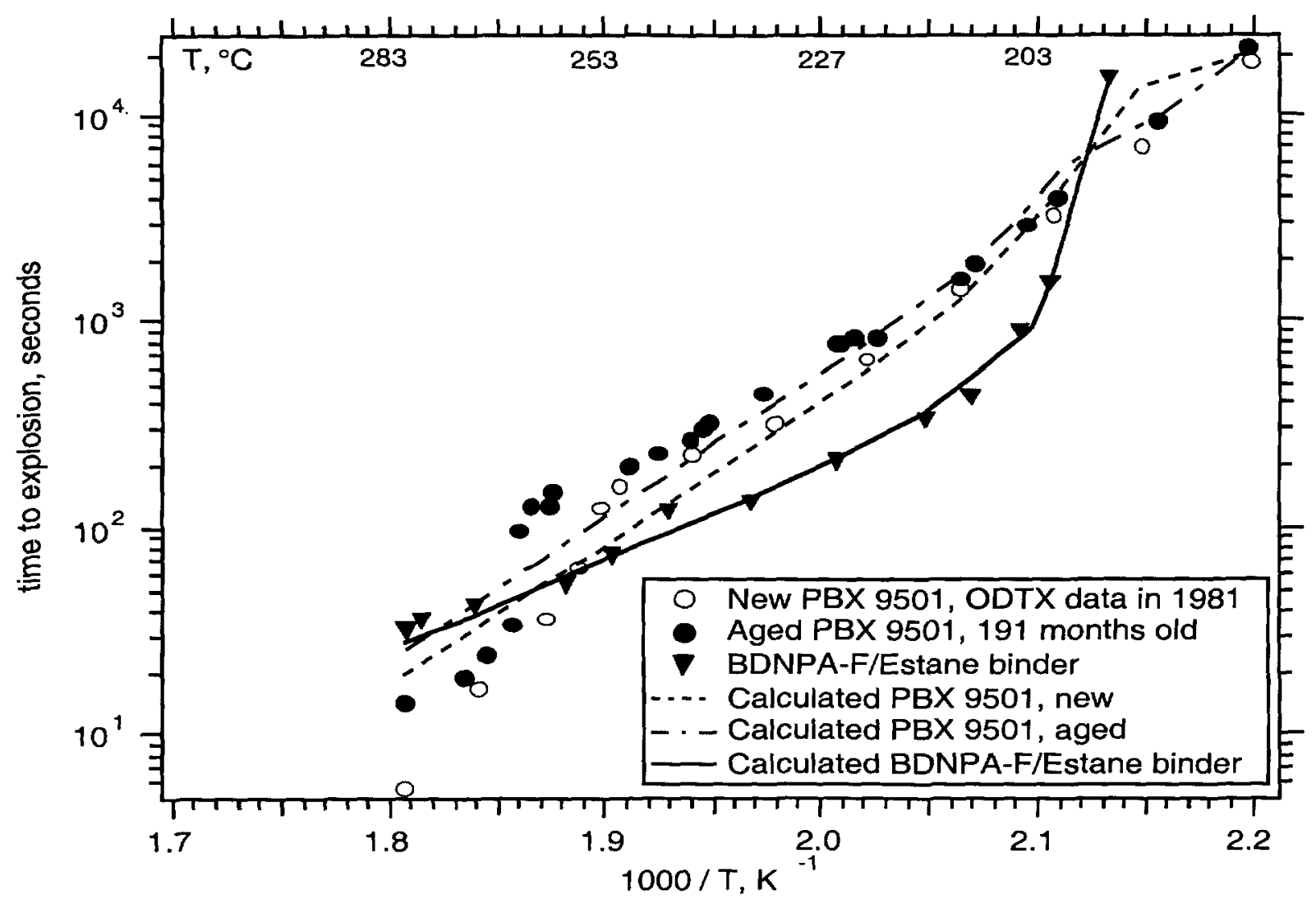

Figure 3. Comparison of the experimental and theoretical treatment of the time to explosion of new and aged PBX 9501 and its binder.

an endothermic process in the model. The results are reported elsewhere (6). Similarly, the modified HMX model fits the data for HMX well (6).

Figure 3 compares the calculated and experimental data for PBX 9501 and its binder. The calculated explosion times fit the experimental data reasonably well up to about $250^{\circ} \mathrm{C}$. The steeper slope at higher temperatures reflects faster decomposition associated with a more complex kinetics in this thermal diffusion-limited region. Differential Scanning Calorimetric (DSC) studies typically showed an exothermic peak above $250^{\circ} \mathrm{C}$ for $\mathrm{HMX}$-based compounds, indicating auto-ignition conditions. This obviously leads to faster decomposition.

The model for aged PBX 9501 is not as straightforward. Factors that affect its thermal decomposition kinetics are not well understood. One approach was to assume a complete loss (migration) of the BDNPA-F component in the composite. In this scenario, this thermally active constituent (see Figure 2) contributes no exothermic energy to the reaction and thus delays the onset reaction temperature. The calculated data for such 'aged' PBX 9501 (without 2.5 wt\% BDNPA-F) fits the experimental results relatively well. While the good agreement between the calculated values and experimentally data may have been coincidental, the current model represents the extreme thermal stability limit resulting from the complete loss of plasticizer from PBX 9501 . Under this scenario, the material is more thermally stable. Experiments are needed to elucidate the various parameters that may influence the material thermal chemistry.

\section{ACKNOWLEDGMENT}

We gratefully acknowledge Richard Simpson for assisting with the testing and David Zevely for machining aged specimens. Steven Chidester provided materials and funding as part of 
Dual Revalidation activities. This work was performed under the auspices of the U.S. Department of Energy by Lawrence Livermore National Laboratory under contract No. W-7405-ENG-48.

\section{REFERENCES}

1. E. Catalano, R. McGuire, E. Lee, E. Wrenn, D. Ornellas, and J. Walton, Sixth Inter. Symposium on Detonation Proceedings, p. 214, Office of Naval Research, ACR-221, Coronado, CA (1976).

2. C. M. Tarver, R. R. McGuire, E. L. Lee, E. W. Wrenn, and K. R. Brein, Seventeenth Symposium (International) on Combustion, Leeds, UK, p. 1407 (1978).

3. P. M. Dickson, B. W. Assay, B. F. Henson, C. S. Fugard, and J. Wong, Shock Compression of Condensed Matter - 1999, edited by M. D. Furnish, et al. AIP Conference Proceedings 505, New York, 1999, Snowbird, Utah, June 27-July 2, 1999, p. 837-840.

4. R. R. McGuire and C. M. Tarver, Seventh International Symposium on Detonation, Naval Surface Weapons Center, Annapolis, MD, p. 56 (1981).

5. T. Tran, L. Simpson, J. Maienschein and C. Tarver, Proceedings of the $32^{\text {nd }}$ International Conference of ICT, 25-1, Karlsruhe, FRG, July 3-6 (2001)

6. C. Tarver and T. Tran, "Thermal Decomposition Kinetics of HMX and HMX-based plastic bonded explosives". In Preparation.

7. J. M. Lightfoot, "PBX 9501 Composition in Production Lots and Surveillance Samples," Mason Hanger Corporation Pantex Plant Report: \#DOE/AL/65030-99-01; Amarillo, TX (1999).

8. T. D. Tran L. R. Simpson, J. L. Maienschein and C. Tarver, $32^{\text {nd }}$ International Annual Conference of ICT Proceeding Volume, 25-1, July 3-6, Karlsruhe, Germany (2001). 